\title{
Enabling Children to Design for Others with Expanded Proxy Design
}

\author{
Oussama Metatla \\ University of Bristol \\ Bristol, UK \\ o.metatla@bristol.ac.uk
}

\author{
Janet C Read \\ Uni. of Central Lancashire \\ Preston, UK \\ JCRead@uclan.ac.uk
}

\author{
Matthew Horton \\ Uni. of Central Lancashire \\ Preston, UK \\ MPLHorton@uclan.ac.uk
}

\begin{abstract}
We explore the question of how child designers can provide design ideas for technology that might reduce the marginalisation that can be experienced by some of their peers. To do this, we introduce the idea of Expanded Proxy Design that moves beyond the notion of "proxies as people" in design, to guide methods for engaging children into thinking about design ideas for a group that exists at some distance from their own experience. We outline three case studies where we made use of such methods. First, we consider expanded proxies in the context of technology and newly immigrant children who are unable to speak in English. Second, we consider the case of designing technology for children with and without visual impairments. Finally, we consider designing playful experiences for children with different temperaments. We reflect on the extent to which this expanded notion of proxies can be used as a meaningful vehicle for overcoming marginalisation and exclusion when children with different abilities design for each other. And we suggest ways to characterise, develop and refine expanded proxy design methods in this broader sense.
\end{abstract}

\section{Author Keywords}

Co-design, Inclusion, Exclusion, Marginalisation, Proxies.

\section{CCS Concepts}

-Human-centered computing $\rightarrow$ Participatory design; Accessibility design and evaluation methods;

\section{INTRODUCTION}

Effective inclusion of children as active designers of technology is a long standing goal of the HCI and IDC research and practice communities. This goal is grounded in the broader motivation, and challenge, to move people in general and children in particular from being mere consumers of technology to becoming more critically engaged with technology that shapes their lives. What is attractive about this research direction is its potential to lead to more meaningful design agendas, which in turn could result in nurturing more inclusive interactions with and through technology. A wide range of literature on interaction design and children demonstrates how children's role in the design of technology has indeed evolved from passive users, to informants and full design partners [17], including recent explorations of children participating in the setting out of evaluating design agendas [63], initiating and driving design processes [73] and becoming full design protagonists [37].

However, despite this general trend towards including children in critiquing and shaping the future of interactive technology, there are still a number of challenges to overcome in order to achieve this goal in practice. For instance, power gaps and biases are known to affect the positioning of child participants in design projects [56], and difficulties of young children in verbalising their thoughts and express their feelings have been shown to create barriers for their full inclusion in decision making processes [70]. Furthermore, the tendency of some design methods to be heavily visual, to require abilities for sustaining attention for long periods of time, or to rely on a need to process verbal cues, all present additional challenges for children who experience situational or permanent sensory, motor and cognitive impairments. Children are also likely to struggle to engage in design processes when these are dedicated to designing very complex technology, to designing for complex behaviour change, or designing for a user group that exists at some distance from the child's own experience - for example the target audience may be a different age, gender, or may have different life experiences.

The above challenges can be broadly grouped under two main strands: finding appropriate means to enhance participants' creative and generative thinking, and supporting effective dialogue and communication between participants. In this paper, we are particularly interested in situations where these challenges are exacerbated because of cases where the knowledge gap between marginalized target groups and children designers may be significant. If technology is being designed to support the inclusion of marginalized children then it is unlikely that children will have much ideas of how best to design for these scenarios. Furthermore, the children engaged in design sessions may have no experience of feeling marginalized so may have little empathy with, or understanding of, the target group.

We explore the question: "How can an expanded notion of proxy design facilitate child designers to provide design ideas for technology that might reduce the marginalisation that can be experienced by some of their peers?". In answer to this question, we thus introduce the notion of Expanded Proxy 
Design as an approach that guides methods for engaging children into thinking about design ideas for a group that exists at some distance from their own experience. We present three case studies where we use such methods, designing for immigrant children who are unable to speak English, designing with and for visually impaired and sighted children, and designing playful interactive experience for children with different temperaments. We contribute outlines of methods for designing through, and an expanded notion of, proxies that move beyond "proxies as people". We provide a characterisation of proxies in these contexts, and reflections on the dynamics of marginalisation, exclusion and inclusion when children with different abilities design for each other. We also discuss ways to characterise, develop and refine proxy design methods.

\section{BACKGROUND}

\section{Co-designing with children}

In 1999, inspired by the tradition of participatory design, Druin et al. [16] described a co-design practice in which children developed skills as designers in a collaborative incremental process. The value in this process was framed from the usercentred design and socio-technical design traditions where designers were encouraged to do what they could to understand their users and to gather the views of their users. In this model, the child designer acts as an informant to the design team (a term introduced by Scaife et al. [59]. A pragmatic view on the value of co-design against this tradition would be to ask the question "What was learned from the children that was used to effect?"

Co-design has become an established practice in the IDC community. Many papers provide insights for others wanting to follow this tradition with rich accounts of co-design sessions that emphasise what was done and what was developed or designed $[67,1])$. Other papers describe methods and techniques for engaging with children with the emphasis in these cases being on the evaluation of the methods against intended gains $[72,69]$. The community has also reflected on the impacts on children of engaging in co-design - these include studies of the empowerment of children [36] and their position as social 'actors' [37], as well as the educational value of such participation [5]. Others look at the roles played by different actors with focus on adult [74] and child roles [60]. The ethics of participation are considered in [55], where the authors critique how children's contributions are considered and included in eventual design briefs.

\section{The challenges of co-design and special needs}

There is a great enthusiasm within HCI to be both inclusive in design practice but also to seek solutions that can improve the lives of individuals. In IDC, there is a large body of work proposing design solutions for children with cognitive and sensory impairments, with physical disabilities and with other developmental difficulties. This list includes, but is not limited to, influential work on neurofeedback brain computer interfaces [2], on visual installations to engage with children with autism [53], on the design of auditory interfaces for blind children [58], and on wearable technology for storytelling for children with cognitive disabilities [23]. A good review of the work done in IDC in this area can be found in [6].
Children from immigrant families and children who are refugees have also been attended to by the IDC community. When designing for these populations a core focus has been to develop technology solutions that bypass language barriers, like the music interface [32], a human-in-the loop translation platform [10] and ebooks [44].

Working with children in co-design is much more challenging when there are cultural, language and situational barriers. Here there are two main tensions - the first is to develop methods and practices that are acceptable and appropriate for these children, and the second is a more pragmatic one which is to what extent these children can express their views - which is primarily a question about having a shared language of expression. Fisher et al. [20] worked with youth in refugee camps, a 'youth first' approach was taken which prioritised the development of the young people (aged 12 - 24) over the desire to gather design ideas. Language was not a main issue in this work, the children were relatively mature, and the work was carried out in Arabic and English. This approach aligns well with the approach taken by Brown and Choi [9] in their work with refugee youths aged 16-20 where they situated their work as salutogenic [3] and care based [66]. They write that 'co-creating with recently settled refugees requires ongoing reflection to ensure that we as designers are worthy of their time and trust, and how we might employ methods that empower them, resulting in designs that are meaningful to their users.'

Korte et al [41] ran a design study with Deaf children aged $3-5$, the authors worked hard to understand the culture of their co-designers, immersing themselves as much as they could manage within the children's local Deaf community, but even then, the authors wrote that this was not really sufficient. Where the main barrier is communication, there have been some workarounds that show some promise. Metatla et al. used sounds as prototyping expressions with adults [47], and used multisensory crafting with both visually impaired and sighted children to co-design inclusive education technologies [48, 49]. McElligott and Van Leeuwen [46] worked with a total of 18 blind and visually impaired children who were engaged as co-designers with the objective to design technology apposite to the needs of those children.

Frauenberger et al. [21] presented a critique on participatory design research with children with special needs, which is a set of reflections from working with children with autism. They highlighted difficulties in terms of recruitment - where looking for children with special needs will inevitably result in low numbers of participants; communication barriers exacerbated by the potential young age of the children and their needs; and gaps in understanding the context of discussion, especially prevalent with some learning disabilities. Kärnä [38] nicely position the needs of children in the centre of their $\mathrm{CiC}$ (Children in the Centre) framework which does require designers to ask - if the children's needs are not being met in a PD context - should they be included? This, together with the challenges highlighted above, points to a suggestion of the use of proxies in co-design. 


\section{Proxies in Design}

The role of proxies is foregrounded in general PD processes (mostly concerning care situations) when no direct participation from the participants is possible or desired [27, 62]. Proxies are described as people close to the intended user (e.g. care personnel, teachers or relatives) who act as mediators for others. Proxies can bridge cultural gaps and thus help with any contextual gaps [42].

Hamidi et al. [31] used proxies in a participatory design study where the children who were intended to benefit from the technology had limited communication. In another study involving adults suffering from aphasia [7], Boyd-Graber et al. drew heavily on the knowledge of proxies, in this case professional speech therapists, to provide them with the necessary information about their patients in order to build a prototype. At Design School Kolding, Herriott [34] ran a co-design project with a local care home where residents were all unable to communicate. They adopted an approach that involved caregivers and taking pictures to make sense of the movement and activities of the residents. They showed how design with proxies in this sense not only produces a particular solution, but also affects the conditions in which it will be used. Moraveji et al. [50] used comicboarding as a participatory design method that uses specially created comic books to help children engage in brainstorming sessions, particularly where traditional design methods may fail in the face of local cultural practices. Teachers of blind and visually impaired children have also been involved in co-design work as proxies, both by themselves when considering materials for visually impaired children [24], and as part of groups including children with and without visual impairments when designing inclusive education technologies [48, 13, 49].

\section{EXPANDING THE NOTION OF PROXIES BEYOND PEOPLE}

In this work, we are interested in exploring whether and how, expanding the notion of proxies beyond only "people", can be used as a meaningful design vehicle for overcoming marginalisation and exclusion when children with different abilities design for each other. There are a number of reasons why this would be a useful expansion on the notion and hence worth investigating in practice.

First, there are situations where "proxies as people" may simply not be available in the given design context or environment.

Second, it is possible that the use of proxies can compound the issues of bias and power balance in design, and so using proxies beyond people can help address these typical design challenges. For instance, designing with caregivers of people with dementia as proxies can sometimes lead to the caregivers taking control of design sessions [33,43], which is problematic as caregivers can be risk adverse and so can reduce opportunities and limit design spaces for the person with dementia $[45,18]$. Third, in the case of designing with and for children, there is also a sense in which children and adults would bring about different ideas and focus to the direction of design agendas. For instance, when co-designing education technologies for children with sensory impairments and their teaching assistants, Metatla et al. [49] found that teaching assistants tended to focus on high level design concerns related, for example, to learning pace and academic stimulation. Children on the other hand were more interested in practical challenges, such as handling lab equipment during lessons and making the aesthetics of the classroom experience accessible. A design proxy that is not a person can therefore help in foregrounding children's interests more strongly. Indeed, young children develop strong attachments to objects such as toys, and even prefer their attachment objects over perfect duplicates [35]. This suggests that using objects as proxies could lead to more engagement in design activities. To evaluate this claim, we outline three case studies where we made use of design methods grounded in this expanded notion of proxy design with and for children in the contexts of technological intervention to address marginalisation and exclusion.

\section{CASE STUDIES}

\section{Case 1: Designing for Mr Hippo Context}

In the UK, as many as 1 in 6 children in primary schools do not speak English as their first language. In some areas, English is a foreign language to more than 70 per cent of 4 to 11 -yearolds, putting enormous pressure on teaching staff. There are also several schools without a single pupil who has English as a first language. This is a rising trend - in 2004, 452,388 primary school children spoke English as a second language. By 2007 this figure had increased by 113,500 , a rise of almost exactly 25 per cent. Today, there are over 1.5 million learners with English as an Additional Language (EAL) in UK maintained schools and many more in independent schools. EAL learners represent just over $21 \%$ of the primary population and nearly $17 \%$ of the secondary population in England.

The problem is not exclusive to the UK, other European countries are experiencing similar trends especially as mobility across Europe increases [75]. A study of immigrant children in Germany showed that these children do less well at school, not just because of their lack of language skills but also due to a lack of socialization [40]. In this work, we aimed to assist children in understanding the causes and impacts of marginalization and thus bring them to a better understanding of methods to reduce exclusion and promote cohesion.

\section{Proxy}

To capture how marginalisation and isolation could be experienced by a child who doesn't speak English in an English speaking school, we used Mr Hippo, a stuffed animal with a particular set of characteristics that emphasise communication barriers. Specifically, Mr Hippo can only speak Hippo, and is unable to use the computer to type because Mr Hippo does not have fingers. Clearly Mr Hippo can be another animal. But some animals are probably better suited in this specific context than others. What is important is that Mr Hippo is lovable, large and endearing. The images of Mr Hippo in Figure 2 give some idea of size and stature.

\section{Design}

Designing for Mr Hippo is done in two stages: Preparation and Play. Preparation takes place before the children get involved; play takes place with the children. To prepare for the session 

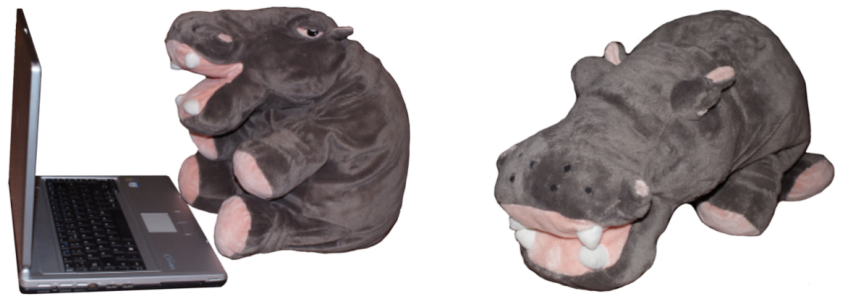

Figure 1. Mr Hippo - showing his size and face

three things are needed: a space where a group of around four children and an adult can work together, a semi-creative but tangible / haptic task (in this instance children were asked to design a game using dominos and playing pieces from board games), and Mr Hippo. Mr Hippo is positioned in the room, sat on a chair at the table of artifacts and the chairs for the children are arranged around the table - then children are brought to the design space.

Before play begins in earnest, the children need to have explained to them what is going on. They are introduced to $\mathrm{Mr}$ Hippo and are told to design, in this instance a game, for $\mathrm{Mr}$ Hippo and then explain it to him so he can play with them, and that the catch is that Mr Hippo only speaks Hippo. The children then design simple games with the artifacts on the table and when they have an idea they are invited to have Mr Hippo play. Mr Hippo is 'manipulated' by either an adult or one of the children and he lets the child know, by his participation or otherwise, how he is doing in understanding what is going on.

The Mr Hippo technique was used with five groups of four children (20 in all) from a class of UK schoolchildren aged 7 and 8. The children came to the event in groups of three, four, or five and were accompanied by a teaching assistant (who tended to take very little part aside from occasionally encouraging the children in the design of their games) and each event was managed by a single researcher (who oversaw all the sessions) and Mr Hippo. Sessions lasted 40 minutes, no formal note-taking was used as the intention was to simply evaluate the technique and see if it was worth further developing. Instead, notes were made straight after the session and the game ideas were noted at the same time.

\section{Outcomes}

Mr Hippo was extremely popular with all the groups. In the first group a child asked if she could hold him and she had him whispering in her ear and telling her what he did or did not understand. Subsequently, seeing how successful this was, the researcher asked each group, once they had settled, if anyone wanted to hold $\mathrm{Mr}$ Hippo and there were no shortages of volunteers. In each group, Mr Hippo attempted to play some of the games but in the later groups some children had Mr Hippo picking up game pieces with his mouth, moving them with his feet and becoming very involved. The last group of the day was almost fighting over Mr Hippo as each member of the group wanted him to play his or her game.
It was because Mr Hippo could only speak Hippo that he was isolated and marginalised. Children took different approaches to try to overcome this but they all realized it was a problem that needed to be solved somehow. Several children asked the researcher if Mr Hippo spoke French or German, and one suggested that he could speak to Mr Hippo in sign language, but each of these solutions was flawed in that the child proposing the solution didn't speak French, German or sign language in any event. Several children tried shouting at Mr Hippo (who reported to his secret friend that he was getting sore ears), and two or three were noted saying 'hippo, hippo, hippo, hippo' to him until it was pointed out that 'human, human, human, human' didn't make much sense.

The children designed games that could be played by one or two (as turn taking or competitively) but many modified them once they realized that Mr Hippo couldn't understand. Strategies that were eventually adopted for conveying the rules of the game included 'designer demonstration', (generally $\mathrm{Mr}$ Hippo didn't'understand this), 'drawing instructions', (only really understood when some sort of timeline was used - like a storyboard), and 'Mr Hippo manipulation', (one of the most successful - this was when the child held Mr Hippo's paws and directed them to do each step.) A very innovative method was seen in the last group when a child played on his own, then had another friend playing, then the third and so on until all the table were playing except Mr Hippo, who then easily understood what to do.

Towards the end of each session, the children were asked to finish up their play and were brought together to think about Mr Hippo. The researcher asked the children what they would do if a hippo arrived at their school tomorrow and they all laughed at the idea but in conversation it transpired that many would want to be friends with the hippo, and some would be scared of him, but it was certainly the case that they would all see he was different. Discussion then moved onto the very real problem, in UK schools, of newly immigrant children from other European countries who are unable to speak in English. At this point the children all realized the connection between designing for Mr Hippo and designing for these children. They started to offer suggestions about how they could play games that the 'marginalised child' could enjoy.

\section{Case 2: Designing for Bobo \& Coco \\ Context}

There are over 25,000 children and young people with visual impairments (VIs) in the UK [52], and 7 out of every 10 of them are today educated in mainstream rather than special schools [57]. This usually takes the form of one or two pupils in a class of up to thirty sighted peers [51]. Including children with special educational needs (SENs) in mainstream schools is a growing trend across a number of countries, often backed by policies that have been in place for a number of years now [68]. However, despite being included with their sighted peers, recent research identified persistent issues with participation [68, 76], reduced opportunities for collaborative learning and social engagement $[4,22]$ and potential for isolation [48]. These challenges are in part attributed to the structural and technical support that VI children receive in 


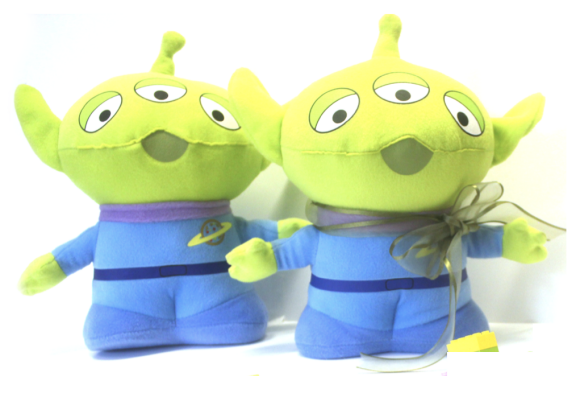

Figure 2. Bobo and Coco - showing their faces. Bobo wears a bow tie.

mainstream schools [48]. In particular, assistive learning technologies are often designed to be used by VI pupils alone and not by sighted peers, and can therefore reduce opportunities for inclusive learning experiences.

Supporting the inclusion of VI children in mainstream schools requires addressing a set of multidimensional and complex concerns. Metatla et al. [48, 49] identified a number of these barriers, which include aspects of learning experience beyond access to learning materials, including social play, structural planning, and mobility. In this case we were particularly interested in the question of blind mobility within schools and its relationship to inclusive interaction between visually impaired and sighted children. Mobility is a core part of physical play activities, and issues of independent mobility could accumulate to constitute barriers to social engagement and inclusive play. Most VI children receive mobility training from a dedicated mobility officer. However, there is no specific technological support for this process. Because significant effort is invested in learning routes, VI children tend to stick to familiar routes, which can lead to reduced opportunities for more adventurous mobility that is key for serendipitous social encounters, including finding friends in the playground and making new ones $[22,48]$. This scenario then formed a core focus of our case study. We therefore aimed to explore the design of novel technology that could help increase inclusive mobility and exploration inside school premises.

\section{Proxy}

Similarly to the case of designing for Mr Hippo, we used stuffed animals as proxies to capture how social isolation and marginalisation could be experienced by children with visual impairments. Bobo and Coco are a set of twin alien creatures (Bobo wears a bow tie). They find themselves in a school because of a spacecraft landing that went wrong. Bobo and Coco get separated from each other during this landing, one lands in the playground, the other inside a classroom, and they need to navigate the school in order to find each other. the catch is that they can't really see very well because their eyes do not function within the Earth atmosphere.

\section{Design}

Designing for Bobo and Coco is also done in two stages: a requirements gathering activity using a variant of bodystorming [11], and a low-tech prototyping activity using a modified version of the Bag of Stuff technique [19]. For this version, a Box of Multisensory Stuff was introduced instead, in which a selection of multisensory materials were organised in a compartmentalised box to make it easier for the children with VIs to keep track of where the materials were located. Both parts of the workshop were linked by a narrative inspired by fictional inquiry [14], developed in consultation with the teaching assistants, involving the alien landing.

The bodystorming session lasted for two hours, where participants moved through school premises, starting from the classroom where Bobo was found, and went across corridors and into the playground to locate Coco and reunite the twin aliens (Figure 3). The researchers moved with the participants to film the session and take occasional notes. The teachers involved were also tasked with keeping notes, which we used together with the video data for later analysis. Participants reflected on challenges and potential solutions to blind and social navigation. The aim of these activities were to both engage children in a common design goal, and to educate sighted children about VI while fostering connections with the VI children $[48,49]$. A key component was to centre the VI children, supported by the proxies set up, as experts at sharing their own experiences to keep the immersion positive, safe, and respectful of everyone's abilities. In the crafting part, which also lasted for two hours participants were divided into three groups, each including three children and one TA. The task was to design technology that would allow Bobo and Coco to navigate effectively and independently through the school premises next time they happen to land there again. Children needed to take into consideration the situational visual impairment that Bobo and Coco experienced and the need to locate and find each other. The crafting session were also filmed, with one researcher taking notes and another taking part in the crafting as a co-designer.

We worked with eight participants: three sighted and three VI children (age 7-9, 3 female) and two VI children's teaching assistants (TAs). We video recorded the bodystorming and crafting sessions, and took observational notes. Video and notes data were analysed using thematic anlaysis [12] following a grounded approach, which enabled us to build themes up as we went through the collected data. Two researchers identified codes and common themes that emerged across a portion of the notes and observational videos, which were then refined and used by one researcher to code the remaining data.

\section{Outcomes}

The children toured the school environment, alerting sighted partners to sounds, textures, and spatial cues they use to navigate and play with the other children. The tours showed the sighted children that their VI peers could complete a task successfully, and it helped to demystify some of the specific techniques that children with VI have developed to navigate their surroundings. E.g. sighted peers discovered how to use echolocation and tactile exploration of floor textures as well as sounds produced by other children in the playground to navigate efficiently.

Together, participants then identified 3 to 4 types of information that should facilitate independent navigation; Fixed and 


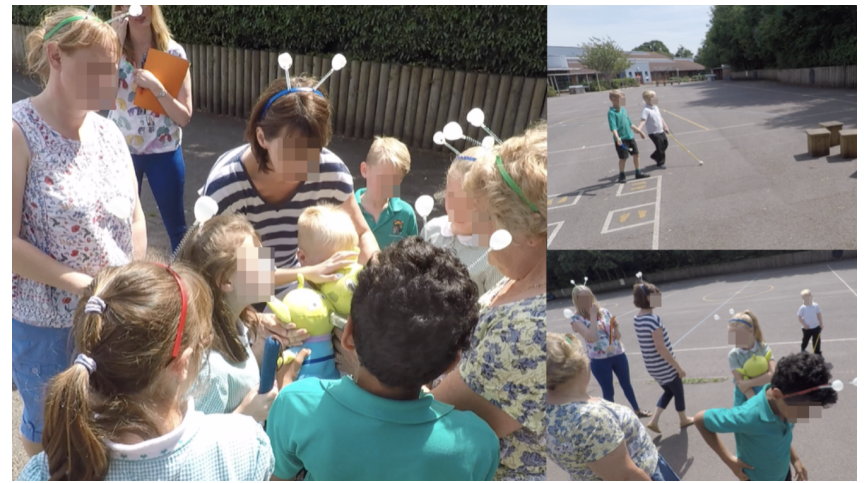

Figure 3. Bobo and Coco use during th bodystorming activity

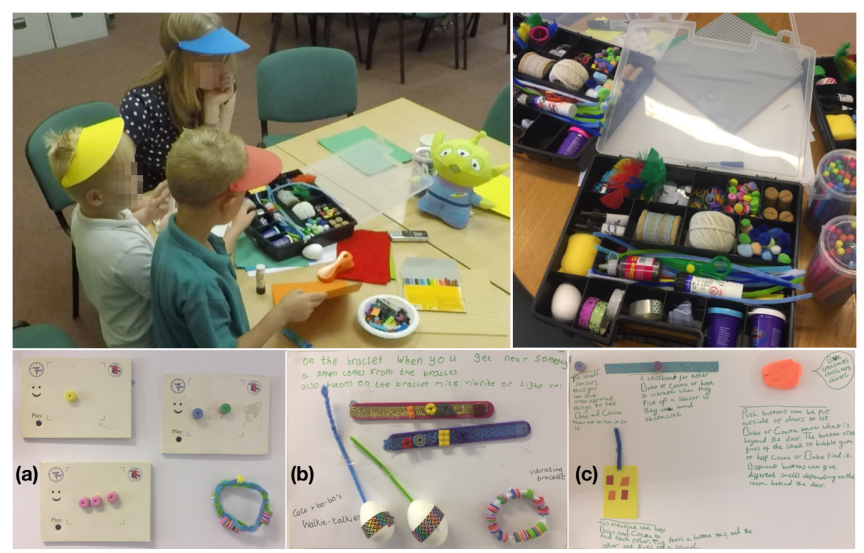

Figure 4. Bobo and Coco - crafting low-fidelity mobility technologies. Children's conceptions of independent mobility kits

Dynamic items, People, and Environment. For instance, inside the classroom, "fixed" items included tables and whiteboards; "dynamic" items were items that changed depending on which lesson is taking place, "people" included children and TAs, and "environment" included knowing where the exit door is located.

Audio was the predominant modality for displaying most of this information. Two kinds of mappings were suggested: sounds should correspond to the type and content of an item; e.g. a knock for table and doors; and sounds should get faster and louder as the alien gets closer to the items they represent. The TAs thought that in busy areas, there may be too much information to convey at once, and so information should be conveyed in either a simple or a complex mode, allowing one to focus on the whole soundscape of the playground or zoom in on particular items. The second predominant modality was tactile, mainly in the form of vibration, but also as tactile floor markers with textures corresponding to different locations, e.g. a rough texture next to the playground door. The participants also thought that vibration should get stronger as the alien gets closer to items. Olfactory display was also suggested as a means for marking locations, e.g. a smell should be displayed as the alien passes by a room to reflect its content, e.g. the smell of old books when passing by the reading room.
Participants designed mobility technology that combined wearables in the form of bracelets and badges, walkie-talkies, and augmented various parts of the school with sensors and interactive buttons. One group designed a bracelet that displayed audio as the alien encounters items and people of interest. They represented this by placing different numbers of sensors on audio recording cards, and recording the accompanying sounds that should be displayed when each sensor is triggered. They also designed an accompanying bracelet with the corresponding number of sensors on each side (Figure 4 (a)). A second group also designed bracelets, their version included multisensory feedback of vibration, lights and smells, in response to items encountered in the environment; they wrote "on the bracelt when you get near something a smell comes from the braclet also buttons on the braclet mite vibrate or light up [sic]" (Figure 4 (b)). The third group decided to design vibrating wristbands that respond to sensors placed on items of interest around the school. They also designed olfactory buttons and a walkie-talkie device that can be worn as a badge and emits auditory guiding beacons (Figure 4 (c)).

These workshop were also opportunities to discover children's interests and to incorporate these back into the design activities. For example, one VI child was fascinated with recording equipment, which served as an entry point for engaging with him during design work. This enthusiasm was manifest in his group's conceptions of the wearable navigation bracelet, in which he contributed recordings of sounds that should be played in response to encounters with sensors blended into the school environment. Another VI child had a learning difficulty, which meant that his group focused on characters with limited sets of multisensory materials. The decision to use alien dolls as proxies was also important to him, mimicking other lessons where we observed similar dolls used to capture his interest and concentration. Throughout the workshop, some of the children were explicit in expressing empathy: "I liked this because you get to find out how different people live and my friends who can't see very well". The use of proxies as part of bodystorming in this case helped introduce elements for building empathy in the initial parts of the design process as a means for preparing all participants for conceptual design in later parts. We observed that this improved both understanding of the design domain and the issues encountered by peers. Children made empathetic references to those experiences when documenting design decisions, highlighting considerations for peers' abilities.

\section{Case 3: Designing for Theory Animals}

\section{Context}

While the previous two case studies focused on specific target groups of children in risk of marginalisation and exclusion, the context for this case study was more broadly on the design of play while exploring children's ability to differentiate in design. The motivation for studying their ability to differentiate was two fold. Firstly to discover if children, when faced with a single design question, could think about it from different perspectives. Secondly to investigate the extent to which the use of proxies, like Mr Hippo and Bobo and Coco, could be used to facilitate children's design in this context. 


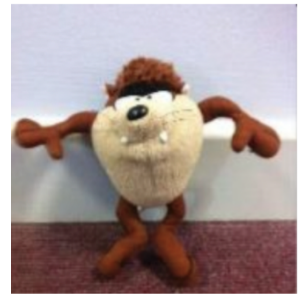

Tasmanian Devil

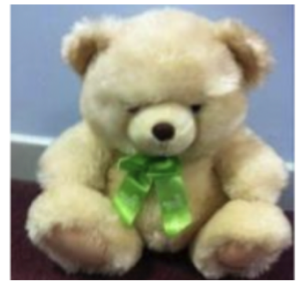

Lovely Bear

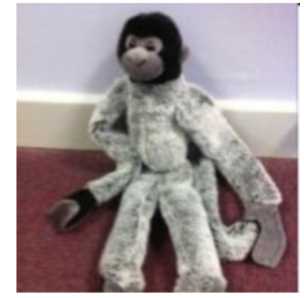

Cheeky Monkey

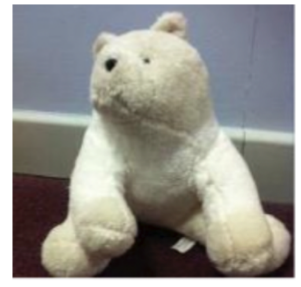

Mr. Polar Bear
Figure 5. The four Theory Animals

A particular interest here was in play given that it is very selfregulated and given that there exist several theories of play and several ways of characterizing play that could be studied and promoted to children. Theories of play fall into two main categories each with a different emphasis - modern theories aim to mainly describe the benefits of play and classical theories tend to focus on the reasons for play. In describing play to children, with the aim of promoting design ideas, unpicking the reasons for play seemed more relevant than a consideration of the benefits. The classical theories include explanations like 'surplus energy' and 'restoration' [15] as well as the idea of play as a preparation for adulthood [28, 29] and play as an act that recreates our previous animal states (recapitulation theory [30]. These latter two theories, when unpicked align well with many of the play activities of young children who are often found to be either playing pretend 'grown up games; or found hurtling around jumping on and off things and generally testing out their physical limitations.

\section{Proxies}

We created a set of proxies in the form of animals, that could represent different 'children' in such a way that it would be expected that other children, thinking about these characters would design quite different play experiences. This was indicated by the literature on play and the literature on temperaments and different characters. Woodrow [71] and others $[8,39]$ propose three dominant images of children as being the innocent child, 'tabula rasa'; a blank slate waiting to be tutored, the evil child needing correction and the child as a miniature adult who is essentially just a small adult rather than a different being.

In deciding which of the above concepts of play could be conveyed to children, the design team took the view that it would be good to aim for diversity and coverage but also were aware that any ideas would have to be easily conveyed to young children. Additionally there was a need to be able to capture the essence of the ideas in animal proxies. Following several discussions it was agreed that a selection of child like and play focused characters would be introduced; these would be the innocent child that 'plays nicely', the naughty child that gets into scrapes, the child who likes to play grown up games and the child who is always climbing up and down things and loves running around. These four 'characters' were then mapped onto four animals - the innocent teddy bear, the naught Tasmanian devil, the grown up polar bear and the climbing monkey. We call these proxies Theory Animals.

\section{Design}

The design session for the Theory Animals took place in a UK primary school with a class of 26 children aged 5 and 6 . All the children in the class took part and the design activity lasted just over an hour. The children worked on tables in the classroom as determined by the class teacher who was in the room for most of the activity but who did not participate and did not get involved in the work. The children were free to move around but mainly worked at the tables where the teacher had situated them.

The researchers brought four furry animals, as described above, to the design event. These were intended to represent the four play motivations described in the earlier section. The researchers also brought materials to the design session namely boxes of stuff including sheets of coloured paper, marker pens, scissors, selotape, pritt stick glue, pens, pencils and photographs of the four different Theory Animals to place on the tables as the children worked.

The design session began with all the children sitting on the carpet and with one of the research team introducing the Theory Animals to the class. Each animal was introduced by name and then a short description of the motivations of the animal was given. For example ' Tasmanian Devil - he is a little bit naughty when he plays, he makes messes and doesn't tidy up he is a bit of a rascal'. They were told that they were going to design a play experience for at least one of the animals. This element of choice was considered important, as we did not believe that all the children would find the task of designing for a character easy. In the introduction, they were told to 'humanise' the Animals rather than focus on their animal abilities (in this way the study was quite different to the cases of $\mathrm{Mr}$ Hippo and Bobo and Coco). This was explained to them in a manner suitable for their age by using an example from one of the researchers own childhood where she used to have the teddy bears play cards with her. Once children were seated they chose one of the Theory Animals to design for, put the picture on their desks and set to work (Figure 6). As each design was completed, the children gave their ideas to the researcher who noted on each completed idea the TheoryAnimal for whom the design was intended and any additional details that helped later understand what the drawing meant to convey. Many children ended up designing for two or more animals.

In order to understand the origin of the designs subsequent analysis was carried out in two phases by a team of three experienced IDC researchers who were not involved in the study. In phase one the question being asked was 'to what extent does this design suit the 'animal' behind the Theory Animal?' and in phase two the question being asked was 'to what extent does this design suit the 'theory' behind the 

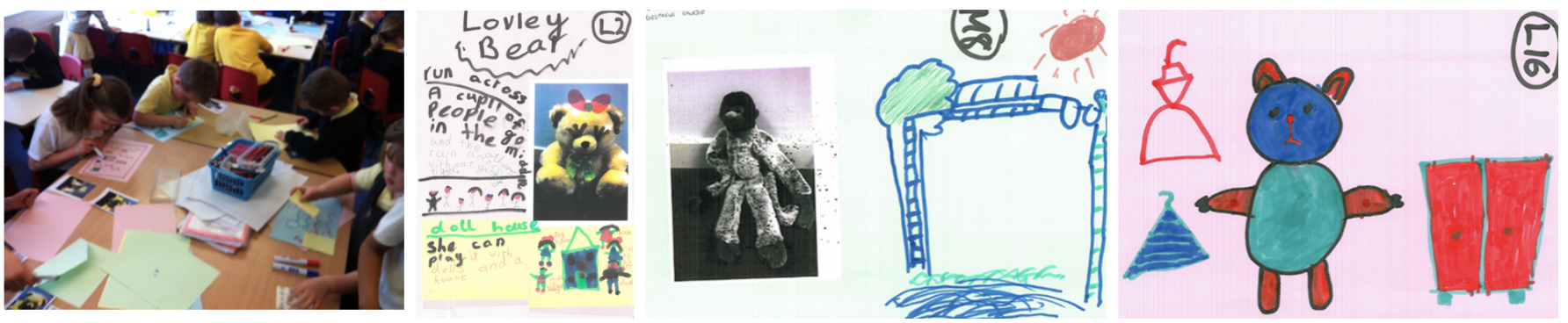

Figure 6. Children working in a group on the activity; Example outcome: Cheeky monkey playing obstacle courses; Lovely bear playing dressing up.

Theory Animal?'. Each design was coded using a five-point Likert scale ranging from positive to negative. The idea behind this was to understand the extent to which the animal and/or theory influenced the design.

\section{Outcomes}

The children designed a variety of play experiences. Once all the play experiences were gathered in there were 52 in total, of these 26 were for the Lovely Bear, 9 for the Polar Bear, 9 for the Tasmanian devil and 8 for the Monkey. That the Lovely Bear was so popular was no surprise. The age of the children in this study predicted the popularity of this character. The extent to which the play activities were described was quite limited as the children were very young and so in order to better understand what the children had designed they were asked to explain their designs as they handed them in.

Children designed a wide range of play activities including dressing up games, disco parties, outdoor games, board games, playing shops and post offices, playing with action toys like zappers, playing in the garden and playing cooking. The activities they chose were typical of the ages of the children. It was interesting, but not surprising; to note that there were no evidences of interactive play experiences. There were no technologies included and no computer games. This is possibly a result of the ages of the children but could also be as the emphasis was on play rather than games. The games designed by the children 'matched' the characteristics of the Theory Animals in almost three quarters of the designs. Figure 6 show some of the designs. For example, a child had pasted the image of the monkey onto the paper and designed in the remaining space. Another child had used all the space for the drawing but had positioned a drawing of the animal in the design.

\section{DISCUSSION}

\section{Expanded Proxy Design}

The proxies used in the three case studies outlined above all acted as mediators of a particular set of conceptual descriptions about a given target group. They essentially provide a fun and easy way for children to begin to understand how to design for users who are not the same as themselves. The proxies are therefore intended to shrink the load on the child designer by reducing the area of design concern. As shown in Figure 7, the concerns of technology and the concerns of different users might add complexity to the design process for children. It is expected that for children to design for marginalised users

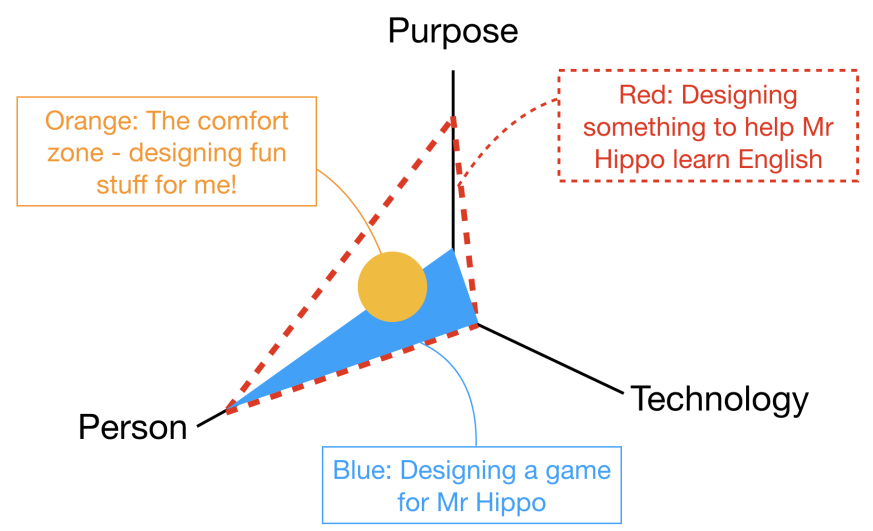

Figure 7. Proxies shrink the load on the child designer by reducing the area of design concern

they will have some difficulties and so teasing the child away from his or her comfort zone is an important feature of the design space and the expanded notion of design proxies as outlined in the three case studies help mediate and support this process.

Mr Hippo and Bobo \& Coco embodied features of the target group that exposed the children designers to a challenge they might not otherwise necessarily consider (speaking Hippo and struggling with Earth atmosphere to see, respectively). The object proxies in this sense did two things: first they challenged the children's norms, and second they them selves acted as a means for navigating the newly imposed norm (e.g. speaking "hippo hippo hippo hippo" to attempt to communicate with Mr Hippo). In the case of Theory Animals, the technique that employed the proxies played a further important role, which is to provide the children with a choice of proxy to engage with and design for. In this case children also were seen to design different play activities for the different animals and this evidences that they were thinking about the "user's"" preferences. Without the Theory Animals the children would have most likely designed for themselves alone. In all cases, the narrative that accompanies the proxies was an important part of using them within this expanded notion in the design process. The narrative was also educational as it, in each case, broadened the children's understanding of others.

We can begin to tease out important ways in which the use of this expanded notion of proxies in the three case studies 


\begin{tabular}{|c|c|c|}
\hline & Traditional notion & Expanded notion \\
\hline What is a proxy? & $\begin{array}{l}\text { People with close personal relationship with } \\
\text { proxied group }\end{array}$ & $\begin{array}{l}\text { Objects with explicit or implicit embodied characteristics of proxied group. } \\
\text { Objects conceptually close to child designers, and not to proxied target group. }\end{array}$ \\
\hline When to use a proxy? & $\begin{array}{l}\text { When no direct participation from the participants } \\
\text { is possible or desired }\end{array}$ & $\begin{array}{l}\text { When the concerns of technology and of different users add complexity to the } \\
\text { design process for children }\end{array}$ \\
\hline How to use a proxy? & $\begin{array}{l}\text { Proxies are interviewed, they participate in design } \\
\text { sessions, answer surveys. } \\
\text { Always involved without direct participation from } \\
\text { proxied target group }\end{array}$ & $\begin{array}{l}\text { Proxies are objects of design, used as props in design activities and } \\
\text { processes. } \\
\text { They can be used with or without participation from proxied target group. }\end{array}$ \\
\hline
\end{tabular}

Figure 8. Traditional vs. expanded notions of proxies in design

moves beyond existing or traditional ways in which the notion of proxies have been used in design thus far, e.g. [31, 7, 34, 24]. And in particular, towards the use of non-human artefacts as proxies, e.g. [50]. Our case studies help in clarifying These differences, which are summarised in Figure 8, broadly defined along answers to the questions of what constitutes a proxy in design; when it should be used; and how.

In terms of the what, existing notions of proxies in design have often referred to actual people who have close relationship, either personal or professional, to the "proxied" or target group. In our proposed expanded notion, proxies are objects with explicit or implicit embodiment of the characteristics of the target group, which makes them conceptually close to the child designers' understanding without necessarily being the target or proxied group as such. This suggests that designers are well advised to make explicit choices both about how to represent characteristics and about which narrative to use to bring these to life. In terms of the question of when to use proxies, existing notions often refer to situations where no direct participation from the target group is either possible or desirable. In contrast to this, the expanded notion we are proposing emphasises the objective of reducing the complexity of the design concerns so that children designers are more able to engage in the design process, so they can better learn and express choice and agency.

Finally, there are also differences in terms of the question of how proxies are used in design. As people with presumed knowledge about the target group, proxies in existing notions of the term often respond to interviews or surveys or participate in design sessions. More often than not, they also participate in processes that do not necessarily include the target group. In contrast, proxies in our expanded notion are objects and props of design activities, props that stimulate creativity but also act as tools of creative exploration and engagement that take place with or without the participation of the target proxied group.

\section{Proxies as a design vehicle}

How does one come up with a proxy?

In each of the three case studies the research team began their activity with background work that included making choices about the proxies to use. In each case these were objects that were familiar to the children and that had humanlike properties.
As described above, the Hippo did not need to be a hippo it was his size and look and feel that made him a successful choice. Aliens were chosen in order that they could explain their situation in the second study and in the third, there was some typification of furry animals to types of play. There was also an element of convenience and size in this case. The animals chosen were all a similar size so as to make them initially equally attractive. It is certainly the case that the proxy used would have an effect. Mr Hippo was NOT an exact representation of a child who would feel alone in a playground; physical reaction to him was not typical of how they might react to an immigrant child. Thus, key trade-offs to consider when choosing a proxy involves consideration for children's understanding vs. representation of who to design for.

\section{How does a proxy address marginalisation and exclusion?}

Choosing a proxy to represent marginalisation and exclusion is not trivial. In these studies the proxies were all complete physically in so far as the visually impaired proxies still had eyes and there were no outward signs of the hippo being unable to speak English. The representation was in fact given in the stories that accompanied the proxies. This could be seen as being very beneficial as indirectly it also addressed the reality of hidden marginalisation and hidden exclusion. The easy conversations around the proxies allowed for open and honest and almost matter of fact conversations with the children about being different.

\section{Reflections on proxies in design}

The three cases here resulted in designs that suited the context and that related well to the situations for which the children were designing. In addition, in each case children were quickly into the design activity and ideas flowed freely. Having the proxy close by during design, and in the TeeoryAnimals case having photos of the proxies close by, kept the children on task. They were seen looking at the proxies for confirmation and, in the case of Mr Hippo, talking to the proxy while focusing on the proxy's needs.

\section{Proxies as metaphors}

The human-like appearance of the proxies gave them personality and an easy means to relate to them. Having eyes, heads etc. encouraged eye to eye contact and interaction. As a metaphor 
for another child, this made them engaging and easy to approach. At the same time they were not children and so did not pose any threat of interruption, interjection or insult.

\section{Proxies as affordances}

As noted elsewhere, the proxies were not 'markedly' different on account of the conditions, situations or characteristics that they were portraying. The differences were only added in the narrative. The children, however, did not 'forget' the characteristics of their proxies, nether did they downplay them - described alongside the proxies at the time of introduction, these characteristics were as obvious to the children as they would have been had they been marked out with bandages, signs and white canes. This the affordances were brought to life in the proxies through the stories that were told.

\section{Proxies vs. personas}

It could be argued that we could have used personas for these studies. A persona is an invented character that is used as an individual to design for and to keep in mind. The proxies here could be considered personas except that in their simplicity they were deliberately not personas in so far as the detail that comes with a personas was very much missing. Children were only told what they needed to know and they were left to imagine all the answers to the rest of the questions they might have. It did not matter if Coco was six or ten, or what his experience of technology was - there was deliberately very little about the proxies that the children had to remember.

Research in psychology and child development has focused on the relationships of children with imaginary companions [25, 64]. An imaginary companion (IC) is defined as "a character, sometimes invisible and sometimes embodied in an object such as a stuffed animal or doll, which is animated by a child and treated as real." [26]. Taylor et al. [65] found that up to $65 \%$ of children have some form of IC by the age of seven. These companions are often given characteristics such as personalities, emotions, intentions and preferences [54] becoming an integral part of a child's daily routine [64]. Our expanded notions of proxies exploited these characteristics to help engage and elicit design ideas from chidlren.

Further, it would seem that the three case studies described here can inform our understanding of how to develop empathy into design practices with children We can reflect on this against the three techniques proposed by Kouprie and Sleeswijk for improving empathy. These are 1 . Direct contact with users, 2. Contact with user data, personas, storytelling etc. and 3. The use of role play. With children, studies have shown [61] that the use of pictures and other data is not so effective at helping children imagine others' lives in design sessions. We believe that expanded proxies are more beneficial than the use of still images and suggest that their use lies in a promising space between direct contact with users and the use of user data. Kouprie and Sleeswijk proposed a stepwise framework to develop empathy which began with the designers having an awareness of other users then suggested they immerse in the worlds of these users, before making an emotional connection with their intended user. With children we accept that this deepest phase may be difficult to achieve but we do consider that the expanded proxies seem to allow for a level of immersion in the life of other child users that might otherwise be more difficult.

\section{Future directions}

The claim in this paper is that the use of playful proxies has enabled children to be empathetic and relaxed about designing for other children who are a little different from themselves. We believe the physicality of these proxies is important but future work needs to test this against virtual avatars and other representations. One surprise in the Mr Hippo study was the playfulness of the children given their ages. There has to date been little work with such proxies with teenage users but this is something that is certainly worth study. Developing useful proxies for mental health work, perhaps aligned to the concepts around Theory Animals could be very beneficial.

\section{CONCLUSION}

This paper investigated the claim that using an expanded notion of proxy design that moves beyond 'proxies as people' can enable children to engage effectively in designing for other children who could be at risk of marginalisation and exclusion. We presented three case studies where we made use of this expanded notion of proxy design and argued that they acted as vehicles for simplifying the design concerns that children engage in in ways that are markedly different from other similar design techniques. The expanded notion of proxies proposed in this paper combines physicalisation and embodiment of relevant features together with appropriate abstraction and accompanying narrative of design briefs and processes. As such, this expanded notion seems to be particularly suited for reducing bias, empowering agencies and balancing participation power when designing with and for children. Future work is needed to provide further validation for this claim, including insights about the extent to which it could also improve design dynamics for other user groups and other design contexts.

\section{ACKNOWLEDGEMENT}

We would to thank the participating school and support services, educators, children and parents, and acknowledge the support of EPSRC Fellowship Grant EP/N00616X/2.

\section{SELECTION AND PARTICIPATION OF CHILDREN}

Children were selected for the Mr Hippo case by the host school when they attended the University for an enrichment day. They were told that the work was part of an EU project and the children participated voluntarily. Children who participated in the Bobo \& Coco case studies were selected by a partner school's Special Education Need Coordinator (SENCo). As per the schools instruction, we used a combination of two mechanisms to obtain consent, a school-based consent system where parents expressed their willingness for their children to take part in research activities, and our own institutional consent mechanism, which was cleared by the authors' institution Ethics Committee, which included commitment to adhere to Data Protection legislation. We provided the SENCo with consent forms and information sheets, which they distributed to parents prior to the work being carried out. We also obtained children's assent to take part in the workshops at the start of each individual workshop. For the Theory Animals case, all 
the children in a Year 1 class of a host school took part as part of their design curriculum within school time. By agreement with the school there was no selection but children were told they did not have to hand in their work. They were told that if they did the work might be used but their names would not be used.

\section{REFERENCES}

[1] Haifa Alhumaidan, Kathy Pui Ying Lo, and Andrew Selby. 2018. Co-designing with children a collaborative augmented reality book based on a primary school textbook. International Journal of Child-Computer Interaction 15 (2018), 24-36.

[2] Alissa N Antle, Leslie Chesick, and Elgin-Skye Mclaren. 2018. Opening up the Design Space of Neurofeedback Brain-Computer Interfaces for Children. ACM Transactions on Computer-Human Interaction (TOCHI) 24, 6 (2018), 1-33.

[3] Aaron Antonovsky. 1996. The salutogenic model as a theory to guide health promotion. Health promotion international 11, 1 (1996), 11-18.

[4] Julie A Bardin and Sandra Lewis. 2008. A survey of the academic engagement of students with visual impairments in general education classes. Journal of Visual Impairment \& Blindness 102, 8 (2008), 472.

[5] Wolmet Barendregt, Tilde M Bekker, Peter Börjesson, Eva Eriksson, and Olof Torgersson. 2016. Legitimate Participation in the Classroom Context: Adding Learning Goals to Participatory Design. In Proceedings of the The 15th International Conference on Interaction Design and Children. 167-174.

[6] Peter Börjesson, Wolmet Barendregt, Eva Eriksson, and Olof Torgersson. 2015. Designing technology for and with developmentally diverse children: a systematic literature review. In Proceedings of the 14th international conference on interaction design and children. 79-88.

[7] Jordan L Boyd-Graber, Sonya S Nikolova, Karyn A Moffatt, Kenrick C Kin, Joshua Y Lee, Lester W Mackey, Marilyn M Tremaine, and Maria M Klawe. 2006. Participatory design with proxies: developing a desktop-PDA system to support people with aphasia. In Proceedings of the SIGCHI Conference on Human Factors in Computing Systems. 151-160.

[8] N Amanda Branscombe. 2000. Early childhood education: A constructivist perspective. (2000).

[9] Alice V Brown and Jaz Hee-jeong Choi. 2018. Refugee and the post-trauma journeys in the fuzzy front end of co-creative practices. In Proceedings of the 15th Participatory Design Conference: Full Papers-Volume 1. $1-11$.

[10] Deana Brown and Rebecca E Grinter. 2016. Designing for transient use: A human-in-the-loop translation platform for refugees. In Proceedings of the 2016 CHI conference on human factors in computing systems. 321-330.
[11] Colin Burns, Eric Dishman, William Verplank, and Bud Lassiter. 1994. Actors, Hairdos \&Amp; Videotape\&Mdash;Informance Design. In Conference Companion on Human Factors in Computing Systems (CHI '94). ACM, New York, NY, USA, 119-120. DOI : http://dx.doi.org/10.1145/259963.260102

[12] Victoria Clarke, Virginia Braun, and Nikki Hayfield. 2015. Thematic analysis. Qualitative psychology: A practical guide to research methods (2015), 222-248.

[13] Clare Cullen and Oussama Metatla. 2019. Co-designing Inclusive Multisensory Story Mapping with Children with Mixed Visual Abilities. In Proceedings of the 18th ACM International Conference on Interaction Design and Children. 361-373.

[14] Christian Dindler and Ole Sejer Iversen. 2007. Fictional inquiry-design collaboration in a shared narrative space. CoDesign 3, 4 (2007), 213-234.

[15] Susan Dockett and Marilyn Fleer. 1999. Play and pedagogy in early childhood: Bending the rules. Harcourst Brace.

[16] Allison Druin, Ben Bederson, Angela Boltman, Adrian Miura, Debby Knotts-Callahan, and Mark Platt. 1998. Children as our technology design partners + . Technical Report.

[17] Allison Druin, Jerry A Fails, and Mona Leigh Guha. 2014. Including children in technology design processes: techniques and practices. In CHI'14 Extended Abstracts on Human Factors in Computing Systems. 1021-1022.

[18] James Edmeads and Oussama Metatla. 2019. Designing for Reminiscence with People with Dementia. In Extended Abstracts of the 2019 CHI Conference on Human Factors in Computing Systems. 1-6.

[19] Jerry Alan Fails, Mona Leigh Guha, Allison Druin, and others. 2013. Methods and techniques for involving children in the design of new technology for children. Foundations and Trends ${ }^{\circledR}$ in Human-Computer Interaction 6, 2 (2013), 85-166.

[20] Karen E Fisher, Katya Yefimova, and Eiad Yafi. 2016. Future's butterflies: Co-designing ICT wayfaring technology with refugee syrian youth. In Proceedings of the The 15th International Conference on Interaction Design and Children. 25-36.

[21] Christopher Frauenberger, Judith Good, and Wendy Keay-Bright. 2011. Designing technology for children with special needs: bridging perspectives through participatory design. CoDesign 7, 1 (2011), 1-28.

[22] Euan Freeman, Graham Wilson, Stephen Brewster, Gabriel Baud-Bovy, Charlotte Magnusson, and Hector Caltenco. 2017. Audible Beacons and Wearables in Schools: Helping Young Visually Impaired Children Play and Move Independently. In Proceedings of the 2017 CHI Conference on Human Factors in Computing Systems. ACM, 4146-4157. 
[23] Franca Garzotto, Mirko Gelsomini, Francesco Clasadonte, Daniele Montesano, and Daniele Occhiuto. 2016. Wearable immersive storytelling for disabled children. In Proceedings of the International Working Conference on Advanced Visual Interfaces. 196-203.

[24] Stéphanie Giraud, Philippe Truillet, Véronique Gaildrat, and Christophe Jouffrais. 2017. "DIY" Prototyping of Teaching Materials for Visually Impaired Children: Usage and Satisfaction of Professionals. In International Conference on Universal Access in Human-Computer Interaction. Springer, 515-524.

[25] Tracy R Gleason. 2002. Social provisions of real and imaginary relationships in early childhood. Developmental psychology 38, 6 (2002), 979.

[26] Tracy R Gleason. 2017. The psychological significance of play with imaginary companions in early childhood. Learning \& behavior 45, 4 (2017), 432-440.

[27] Erik Grönvall and Stefan Lundberg. 2014. On challenges designing the home as a place for care. In Pervasive Health. Springer, 19-45.

[28] Karl Groos. 1898. The play of animals. D. Appleton and Company.

[29] Karl Groos. 1908. The play of man. D. Appleton.

[30] GS Hall. 1906. Youth: Its education, regimen, and hygiene. New York, NY: D. (1906).

[31] Foad Hamidi, Melanie Baljko, and Isabel Gómez. 2017. Using participatory design with proxies with children with limited communication. In Proceedings of the 19th International ACM SIGACCESS Conference on Computers and Accessibility. 250-259.

[32] K Heikkinen, P Kallonen, J Paananen, R Porras, Ross Purves, JC Read, T Rinta, and G Welch. 2015. Designing mobile applications for children. User Requirements Wireless 42, 7 (2015).

[33] Niels Hendriks, Liesbeth Huybrechts, Andrea Wilkinson, and Karin Slegers. 2014. Challenges in doing participatory design with people with dementia. In Proceedings of the 13th Participatory Design Conference: Short Papers, Industry Cases, Workshop Descriptions, Doctoral Consortium papers, and Keynote abstracts-Volume 2. 33-36.

[34] Richard Herriott. 2015. The use of proxies: lessons of social co-design for inclusive design for people with cognitive disabilities. Journal of accessibility and design for all 5, 2 (2015), 100-124.

[35] Bruce M Hood and Paul Bloom. 2008. Children prefer certain individuals over perfect duplicates. Cognition 106, 1 (2008), 455-462.

[36] Netta Iivari and Kari Kuutti. 2018. Critical design in interaction design and children: impossible, inappropriate or critical imperative?. In Proceedings of the 17th ACM Conference on Interaction Design and Children. 456-464.
[37] Ole Sejer Iversen, Rachel Charlotte Smith, and Christian Dindler. 2017. Child as protagonist: Expanding the role of children in participatory design. In Proceedings of the 2017 Conference on Interaction Design and Children. 27-37.

[38] Eija Kärnä, Jussi Nuutinen, Kaisa Pihlainen-Bednarik, and Virpi Vellonen. 2010. Designing technologies with children with special needs: Children in the Centre (CiC) framework. In Proceedings of the 9th International Conference on Interaction Design and Children. 218-221.

[39] Mary Jane Kehily. 2008. An introduction to childhood studies. McGraw-Hill Education (UK).

[40] Werner Knapp. 2006. Language and learning disadvantages of learners with a migrant background in Germany. In Intergovernmental Conference Languages of Schooling: Towards a Framework for Europe. 16-18.

[41] Jessica Korte, Leigh Ellen Potter, and Sue Nielsen. 2017. The impacts of Deaf culture on designing with Deaf children. In Proceedings of the 29th Australian Conference on Computer-Human Interaction. 135-142.

[42] Paola Lanzi, Patrizia Marti, Simone Pozzi, and Petra Scrivani. 2004. Users as cultural mediators in interactive system design. In Living and Working with Technology, Proceedings of the twelfth European conference on cognitive ergonomics, ECCE12.

[43] Stephen Lindsay, Katie Brittain, Daniel Jackson, Cassim Ladha, Karim Ladha, and Patrick Olivier. 2012. Empathy, participatory design and people with dementia. In Proceedings of the SIGCHI Conference on Human Factors in Computing Systems. 521-530.

[44] Rebecca Linke, Tina Kothe, and Florian Alt. 2017. TaBooGa: A hybrid learning app to support children's reading motivation. In Proceedings of the 2017 Conference on Interaction Design and Children. 278-285.

[45] Julia M Mayer and Jelena Zach. 2013. Lessons learned from participatory design with and for people with dementia. In Proceedings of the 15th international conference on Human-computer interaction with mobile devices and services. 540-545.

[46] Joanne McElligott and Lieselotte Van Leeuwen. 2004. Designing sound tools and toys for blind and visually impaired children. In Proceedings of the 2004 conference on Interaction design and children: building a community. 65-72.

[47] Oussama Metatla, Nick Bryan-Kinns, Tony Stockman, and Fiore Martin. 2015. Designing with and for people living with visual impairments: audio-tactile mock-ups, audio diaries and participatory prototyping. CoDesign 11, 1 (2015), 35-48. 
[48] Oussama Metatla and Clare Cullen. 2018. "Bursting the Assistance Bubble" Designing Inclusive Technology with Children with Mixed Visual Abilities. In Proceedings of the 2018 CHI Conference on Human Factors in Computing Systems. 1-14.

[49] Oussama Metatla, Alison Oldfield, Taimur Ahmed, Antonis Vafeas, and Sunny Miglani. 2019. Voice user interfaces in schools: Co-designing for inclusion with visually-impaired and sighted pupils. In Proceedings of the 2019 CHI Conference on Human Factors in Computing Systems. 1-15.

[50] Neema Moraveji, Jason Li, Jiarong Ding, Patrick O'Kelley, and Suze Woolf. 2007. Comicboarding: using comics as proxies for participatory design with children. In Proceedings of the SIGCHI conference on Human factors in computing systems. 1371-1374.

[51] Marian Morris and Paula Smith. 2008. Educational provision for blind and partially sighted children and young people in England: 2007. National Foundation for Educational Research (NFER) for RNIB (2008).

[52] ONS. 2015. National Population Projections for 2015, 2012-based projections release. Office for National Statistics (2015).

[53] Narcís Parés, Anna Carreras, Jaume Durany, Jaume Ferrer, Pere Freixa, David Gómez, Orit Kruglanski, Roc Parés, J Ignasi Ribas, Miquel Soler, and others. 2005. Promotion of creative activity in children with severe autism through visuals in an interactive multisensory environment. In Proceedings of the 2005 conference on Interaction design and children. 110-116.

[54] Jean Piaget. 1929. Selected Works: The Child's Conception of the World. Routledge.

[55] Janet C Read, Daniel Fitton, and Matthew Horton. 2014. Giving ideas an equal chance: inclusion and representation in participatory design with children. In Proceedings of the 2014 conference on Interaction design and children. 105-114.

[56] Janet C Read, Peggy Gregory, Stuart MacFarlane, Barbara McManus, Peter Gray, and Raj Patel. 2002. An investigation of participatory design with children-informant, balanced and facilitated design. In Interaction design and Children. Eindhoven, 53-64.

[57] RNIB. 2013. Key statistics on the prevalence and population of children and young people with vision impairment. (2013).

[58] Jaime Sánchez, Mauricio Lumbreras, and Luca Cernuzzi. 2001. Interactive virtual acoustic environments for blind children: computing, usability, and cognition. In CHI'O1 Extended Abstracts on Human Factors in Computing Systems. 65-66.

[59] Michael Scaife, Yvonne Rogers, Frances Aldrich, and Matt Davies. 1997. Designing for or designing with? Informant design for interactive learning environments. In Proceedings of the ACM SIGCHI Conference on Human factors in computing systems. 343-350.
[60] Selina Schepers, Katrien Dreessen, and Bieke Zaman. 2018. Rethinking children's roles in Participatory Design: The child as a process designer. International journal of child-computer interaction 16 (2018), 47-54.

[61] Gavin Sim, Janet C Read, and Matthew Horton. 2017. Children Designing Serious Games for Children from other Cultures. EAI Endorsed Transactions on Serious Games 4, 12 (2017).

[62] Marie Sjölinder, Isabella Scandurra, Anneli Avatare Nou, and Ella Kolkowska. 2017. Using care professionals as proxies in the design process of welfare technology-Perspectives from municipality care. In International Conference on Human Aspects of IT for the Aged Population. Springer, 184-198.

[63] Katta Spiel, Laura Malinverni, Judith Good, and Christopher Frauenberger. 2017. Participatory evaluation with autistic children. In Proceedings of the 2017 CHI Conference on Human Factors in Computing Systems. 5755-5766.

[64] Marjorie Taylor. 1999. Imaginary companions and the children who create them. Oxford University Press on Demand.

[65] Marjorie Taylor, Stephanie M Carlson, Bayta L Maring, Lynn Gerow, and Carolyn M Charley. 2004. The characteristics and correlates of fantasy in school-age children: imaginary companions, impersonation, and social understanding. Developmental psychology 40, 6 (2004), 1173.

[66] Austin Toombs, Shad Gross, Shaowen Bardzell, and Jeffrey Bardzell. 2017. From empathy to care: a feminist care ethics perspective on long-term researcher-participant relations. Interacting with Computers 29, 1 (2017), 45-57.

[67] Maarten Van Mechelen, Bieke Zaman, Lizzy Bleumers, and Ilse Mariën. 2019. Designing the Internet of Toys for and with Children: A Participatory Design Case Study. In The Internet of Toys. Springer, 181-203.

[68] Giacomo Vivanti, Ed Duncan, Geraldine Dawson, and Sally J Rogers. 2017. Facilitating Learning Through Peer Interactions and Social Participation. In Implementing the Group-Based Early Start Denver Model for Preschoolers with Autism. Springer, 87-99.

[69] Greg Walsh, Alison Druin, Mona Leigh Guha, Elizabeth Foss, Evan Golub, Leshell Hatley, Elizabeth Bonsignore, and Sonia Franckel. 2010. Layered elaboration: a new technique for co-design with children. In Proceedings of the SIGCHI Conference on Human Factors in Computing Systems. 1237-1240.

[70] Cara Wilson, Margot Brereton, Bernd Ploderer, and Laurianne Sitbon. 2019. Co-Design Beyond Words: 'Moments of Interaction'with Minimally-Verbal Children on the Autism Spectrum. In Proceedings of the 2019 CHI Conference on Human Factors in Computing Systems. 1-15. 
[71] Christine Woodrow. 1999. Revisiting images of the child in early childhood education: Reflections and considerations. Australasian Journal of Early Childhood 24, 4 (1999), 7-12.

[72] Jason Yip, Tamara Clegg, Elizabeth Bonsignore, Helene Gelderblom, Emily Rhodes, and Allison Druin. 2013a. Brownies or bags-of-stuff? Domain expertise in cooperative inquiry with children. In Proceedings of the 12th International Conference on Interaction Design and Children. 201-210.

[73] Jason C Yip, Elizabeth Foss, Elizabeth Bonsignore, Mona Leigh Guha, Leyla Norooz, Emily Rhodes, Brenna McNally, Panagis Papadatos, Evan Golub, and Allison Druin. 2013b. Children initiating and leading cooperative inquiry sessions. In Proceedings of the 12th
International Conference on Interaction Design and Children. 293-296.

[74] Jason C Yip, Kiley Sobel, Caroline Pitt, Kung Jin Lee, Sijin Chen, Kari Nasu, and Laura R Pina. 2017.

Examining adult-child interactions in intergenerational participatory design. In Proceedings of the 2017 CHI Conference on Human Factors in Computing Systems. 5742-5754.

[75] Tiedao Zhang. 2005. Integrating Immigrant Children into Schools in Europe. (2005).

[76] Li Zhou, Amy T Parker, Derrick W Smith, and Nora Griffin-Shirley. 2011. Assistive technology for students with visual impairments: Challenges and needs in teachers' preparation programs and practice. J. Visual Impairment \& Blindness 105, 4 (2011), 197. 